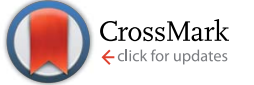

Cite this: Chem. Sci., 2016, 7, 1205

\title{
Rhodium-catalyzed asymmetric synthesis of silicon-stereogenic silicon-bridged arylpyridinones $\uparrow$
}

\author{
Ryo Shintani, ${ }^{*}$ Ryo Takano and Kyoko Nozaki* \\ A rhodium-catalyzed regio- and enantioselective synthesis of silicon-stereogenic silicon-bridged \\ arylpyridinones has been developed through $[2+2+2]$ cycloaddition of silicon-containing prochiral \\ triynes with isocyanates. High yields and enantioselectivities have been achieved by employing an axially \\ chiral monophosphine ligand, and this process could be applied to catalytic asymmetric synthesis of \\ silicon-stereogenic chiral polymers for the first time. The reaction mechanism of the present catalysis \\ has also been experimentally investigated to establish a reasonable catalytic cycle, advancing the \\ mechanistic understanding of the rhodium-catalyzed pyridinone synthesis by $[2+2+2]$ cycloaddition \\ reactions.
}

Received 5th October 2015

Accepted 6th November 2015

DOI: $10.1039 / \mathrm{c} 5 \mathrm{sc03767k}$

www.rsc.org/chemicalscience

with internal alkynes. ${ }^{5, \boldsymbol{6}}$ By taking advantage of the convergent nature of this intermolecular approach, we decided to further explore the enantioselective synthesis of a new family of siliconstereogenic silicon-bridged $\pi$-conjugated compounds based on this strategy. Specifically, in this article, we describe the development of a catalytic regio- and enantioselective synthesis of silicon-stereogenic silicon-bridged arylpyridinones, dihydrobenzosilolopyridinones, by rhodium-catalyzed $[2+2+2]$ cycloaddition of prochiral silicon-containing triynes with isocyanates, including the investigation of its mechanistic aspects. $^{7,8}$

through asymmetric catalysis. ${ }^{2,3}$ Because organosilanes are widely utilized in various fields of research, broadening the scope of accessible silicon-stereogenic enantioenriched organosilanes would be highly desirable. Among the known catalytic enantioselective methods for the creation of silicon stereocenters, most typical approach is the desymmetrization of prochiral dihydrodiorganosilanes by way of enantiopositionselective hydrosilylation or other $\mathrm{Si}-\mathrm{H}$ bond functionalization reactions. ${ }^{4}$ In contrast, the use of other types of prochiral organosilanes as substrates has been much less explored and such examples started to appear only very recently, ${ }^{5}$ many of which are intramolecular processes.

As one of the rare examples of intermolecular reactions, we recently reported a rhodium-catalyzed asymmetric synthesis of silicon-stereogenic dibenzosiloles (silicon-bridged biaryls) by enantioselective $[2+2+2]$ cycloaddition of prochiral triynes

\footnotetext{
Department of Chemistry and Biotechnology, Graduate School of Engineering, The University of Tokyo, 7-3-1 Hongo, Bunkyo-ku, Tokyo 113-8656, Japan. E-mail: shintani@chembio.t.u-Tokyo.ac.jp; nozaki@chembio.t.u-tokyo.ac.jp; Fax: +81-35841-7263; Tel: +81-3-5841-7261

$\dagger$ Electronic supplementary information (ESI) available: Detailed experimental procedures. CCDC 1428796. For ESI and crystallographic data in CIF or other electronic format see DOI: $10.1039 / \mathrm{c} 5 \mathrm{sc} 03767 \mathrm{k}$
}

\section{Results and discussion}

\section{Reaction development}

As a starting point, we employed prochiral triyne 1a as a model substrate for the cationic rhodium-catalyzed $[2+2+2]$ cycloaddition with phenyl isocyanate (2a) in the presence of $(R)$ binap ${ }^{9}$ as the ligand at $25{ }^{\circ} \mathrm{C}$ (Table 1, entry 1). Although potentially two regioisomers $3 \mathbf{a a}$ and $3 \mathbf{a a}^{\prime}$ could be obtained depending on the orientation of isocyanate $2 \mathbf{a}$, the reaction selectively provided only 3 aa in 93\% yield, albeit with low enantiomeric excess (14\% ee). The change of ligand to $(R)-\mathrm{H}_{8}-$ binap $^{\mathbf{1 0}}$ gave similarly low enantioselectivity (13\% ee; entry 2 ), whereas the use of $(R)$-segphos ${ }^{\mathbf{1 1}}$ improved the enantioselectivity to $76 \%$ ee (entry 3 ). But, the ee was not further improved by using $(R)$-dm-segphos (68\% ee; entry 4$)$. In comparison to these axially chiral bisphosphine ligands, axially chiral monophosphine ligand $(R)-\mathrm{MeO}-\mathrm{mop}^{12}$ gave 3aa with higher enantioselectivity ( $80 \%$ ee; entry 5 ), and the use of $(R)$-L having a methyl group at the $3^{\prime}$-position ${ }^{13}$ further improved the enantioselectivity of 3 aa to $89 \%$ ee in $85 \%$ yield (entry 6 ). It is worth noting that only 3aa was obtained without forming its 
Table 1 Rhodium-catalyzed asymmetric [2+2+2] cycloaddition of 1a with 2a: ligand effect

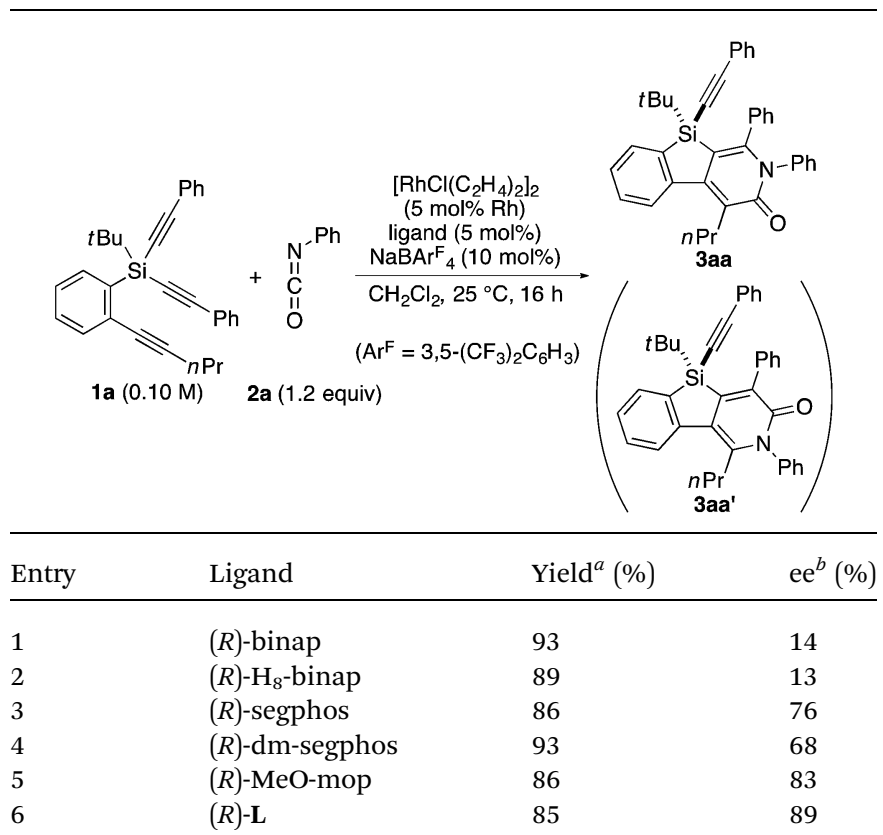<smiles>Pc1cccc(-c2c(P)ccc3c2CCCC3)c1-c1c(P)ccc2c1CCCC2</smiles>

(R)-H -binap (R)-dm-segphos: $\mathrm{Ar}=3,5-\mathrm{Me}_{2} \mathrm{C}_{6} \mathrm{H}_{3}$<smiles>COc1ccc2ccccc2c1-c1c(-c2ccccc2)ccc2ccccc12</smiles>

(R)-MeO-mop

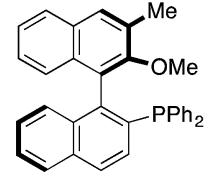

$(R)-\mathbf{L}$

${ }^{a}$ Isolated yield. ${ }^{b}$ Determined by chiral HPLC on a Chiralpak IA column with hexane/2-propanol $=95 / 5$.

regioisomer 3aa' for all of these reactions, and the structure of 3aa including the absolute configuration was firmly established by $\mathrm{X}$-ray crystallographic analysis with $\mathrm{Cu}-\mathrm{K} \alpha$ radiation as shown in Fig. 1 after recrystallization of the product obtained in entry $6 .^{14}$

Under the conditions described in Table 1 , entry 6 , various silicon-stereogenic dihydrobenzosilolopyridinones (siliconbridged arylpyridinones) 3 can be synthesized with high yields and enantioselectivities as summarized in Table 2. Thus, 1pentynyl group of 1a (entry 1) can be replaced by other alkynyl groups such as 1-propynyl (1b), 4-methyl-1-pentynyl (1c), and unsubstituted ethynyl (1d) groups to give compounds 3ba-3da in $76-85 \%$ yield with $88-91 \%$ ee (entries $2-4$ ). Replacement of tert-butyl group on the silicon atom by less bulky cyclohexyl group (1e) also provides the corresponding product 3ea with relatively high ee of $86 \%$ (entry 5), but the reaction of alkoxysubstituted substrate $\mathbf{1}$ f gives almost racemic product $\mathbf{3 f a}$ under the present reaction conditions (entry 6). Triynes having two of

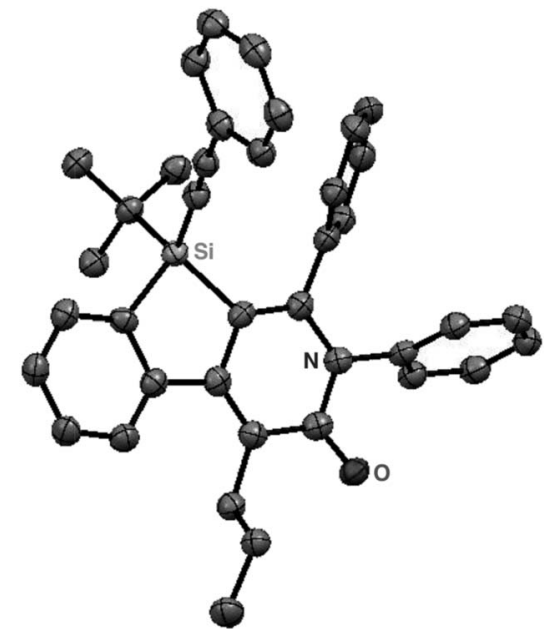

Fig. 1 X-Ray crystal structure of $(R)$-3aa (Flack parameter $=0.04(4)$ ). Hydrogen atoms are omitted for clarity.

Table 2 Scope of rhodium-catalyzed asymmetric synthesis of siliconbridged arylpyridinones 3

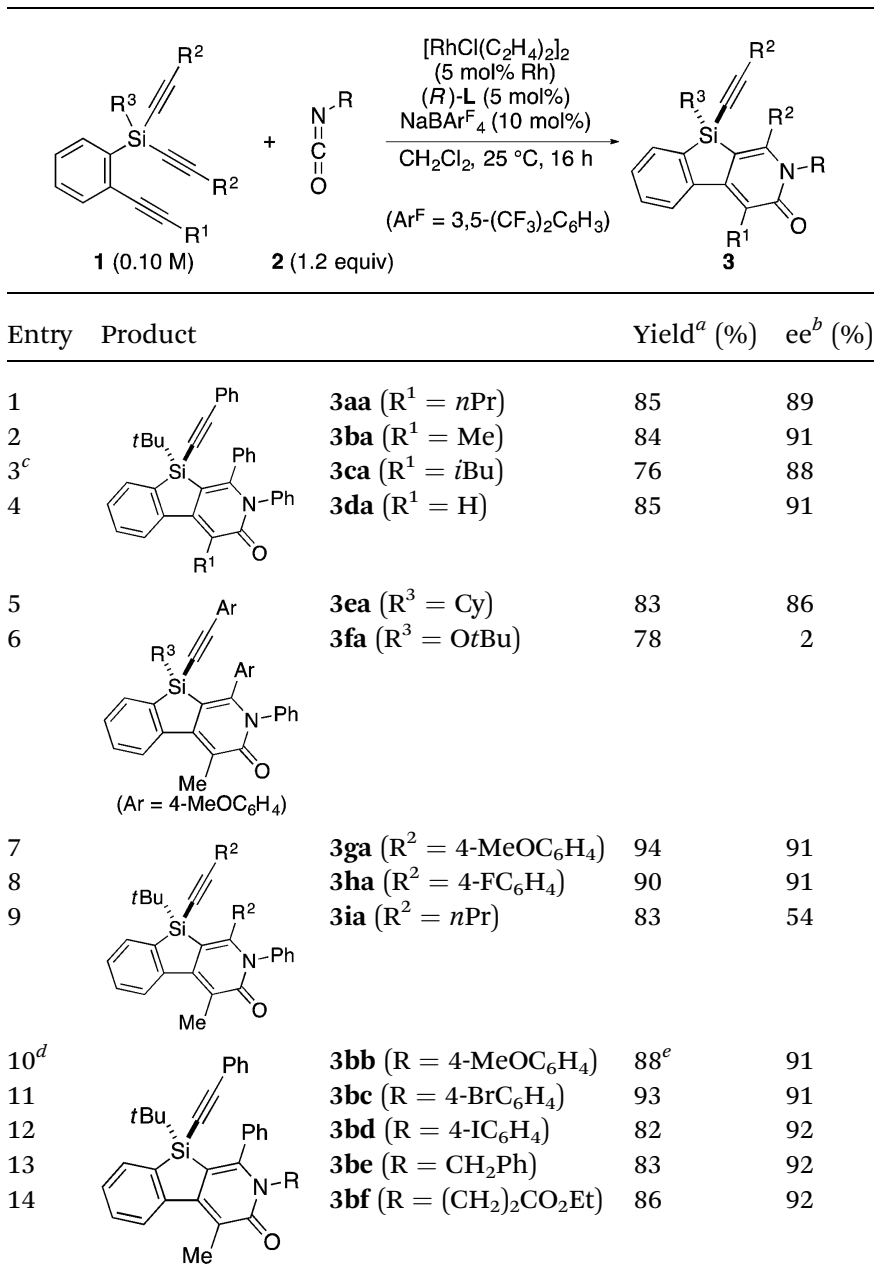

${ }^{a}$ Isolated yield. ${ }^{b}$ Determined by chiral HPLC. ${ }^{c}$ The reaction was conducted at $35{ }^{\circ} \mathrm{C}$ for $37 \mathrm{~h} .{ }^{d}$ The reaction was conducted with 1.1 equiv. of $2 \mathbf{b}$. ${ }^{e}$ Containing $c a$. $3 \%$ of inseparable impurity. 
the same substituted phenylethynyl groups on the silicon atom (19 and $\mathbf{1 h}$ ) are also suitable substrates for the reaction with isocyanate $\mathbf{2 a}$ to give $\mathbf{3 g a}$ and $\mathbf{3 h a}$ with high enantiomeric excesses (91\% ee; entries 7 and 8), but the use of an alkylethynyl-substituted variant (1i) results in the formation of product 3ia with lower enantioselectivity (54\% ee; entry 9). With regard to the isocyanate, not only aryl isocyanates (2b-2d) but also alkyl isocyanates (2e and $2 \mathbf{f}$ ) possessing functional groups such as halides and esters can be efficiently employed in the present catalysis to give $\mathbf{3 b} \mathbf{b}-\mathbf{3 b f}$ in uniformly high yields (82-93\% yield) with $91-92 \%$ ee (entries 10-14). It is worth mentioning again that all of these reactions proceed with complete regioselectivity irrespective of the substrate combination. In addition to these $N$-arylated or $N$-alkylated products $3, N$-H compound 4 can also be accessed by treatment of ethoxycarbonylethyl-substituted compound 3 bf $(92 \%$ ee) with $\mathrm{NaH}$ followed by protonation via a retro-Michael addition reaction (73\% yield, 92\% ee; eqn (1)). ${ }^{15}$

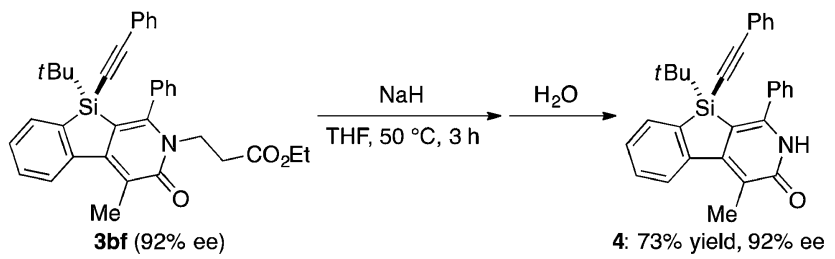

(1)

\section{Synthesis of a silicon-stereogenic chiral polymer}

The complete regioselectivity in the present $[2+2+2]$ cycloaddition led us to investigate the preparation of enantioenriched chiral polymers based on the silicon-stereogenic center of silicon-bridged arylpyridinones. For example, the asymmetric $[2+2+2]$ cycloaddition reaction of trimethylsilylethynyl-substituted compound $\mathbf{1 j}$ with 4 -iodophenyl isocyanate (2d) under $\mathrm{Rh} /(R)$-L catalysis gave product $\mathbf{3 j d}$ in $84 \%$ yield with $89 \%$ ee (eqn (2)). Subsequent removal of the trimethylsilyl group followed by recrystallization led to bifunctional monomer 5 with 99\% ee in a good overall yield. The Sonogashira coupling polymerization of 5 in the presence of $3 \mathrm{~mol} \%$ of methyl 4-iodobenzoate as an initiator successfully afforded poly-5 in 93\% yield with control of the number average molecular weight $\left(M_{\mathrm{n}}=19000 \mathrm{~g} \mathrm{~mol}^{-1}\right.$, i.e., degree of polymerization $=35$; eqn (3)). ${ }^{\mathbf{1 6}}$ As far as we are aware, this represents the first example of the synthesis of silicon-stereogenic chiral polymers based on the catalytic asymmetric construction of the silicon stereocenter. ${ }^{17}$ The UV-vis and fluorescence spectra of poly-5 are shown in Fig. 2: the UV-vis absorption and emission band maxima are at $352 \mathrm{~nm}$ and $440 \mathrm{~nm}$, respectively, both of which are significantly redshifted compared to the reported silicon-stereogenic chiral conjugated polymer. ${ }^{17 a}$ We also examined the CD spectrum of poly-5 and found that it showed negative Cotton effects at $287 \mathrm{~nm}\left(\Delta \varepsilon=-10.7\right.$ unit-M $\left.\mathrm{M}^{-1} \mathrm{~cm}^{-1}\right)$ and $237 \mathrm{~nm}(\Delta \varepsilon=-22.4$ unit-M $\mathrm{M}^{-1} \mathrm{~cm}^{-1}$ ) (Fig. 3).

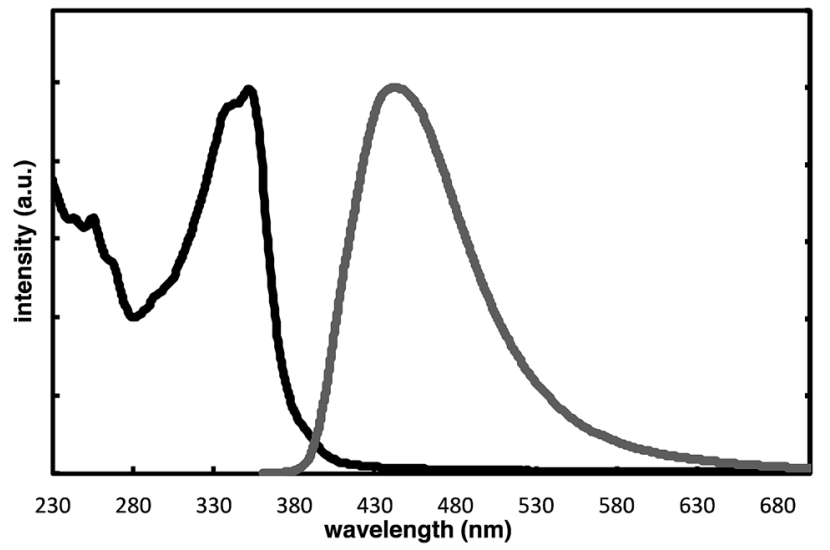

Fig. 2 Normalized UV-vis (black line; at $1.7 \times 10^{-5}$ unit-M) and fluorescence spectra (gray line $\left(\Phi_{\mathrm{F}}=0.04\right)$; at $1.7 \times 10^{-5}$ unit-M; excited at $350 \mathrm{~nm}$ ) of poly-5 in $\mathrm{CH}_{2} \mathrm{Cl}_{2}$ at $25^{\circ} \mathrm{C}$.

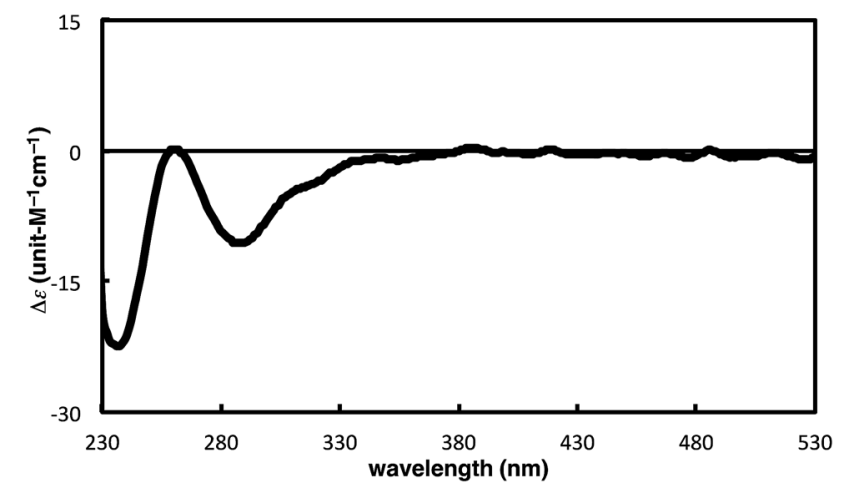

Fig. $3 \mathrm{CD}$ spectrum of poly-5 (at $1.7 \times 10^{-5}$ unit-M) in $\mathrm{CH}_{2} \mathrm{Cl}_{2}$ at $25^{\circ} \mathrm{C}$.

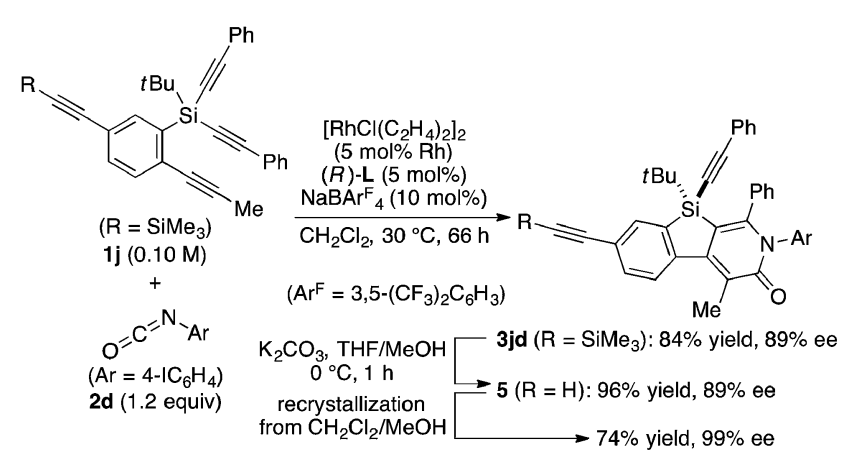

(2)

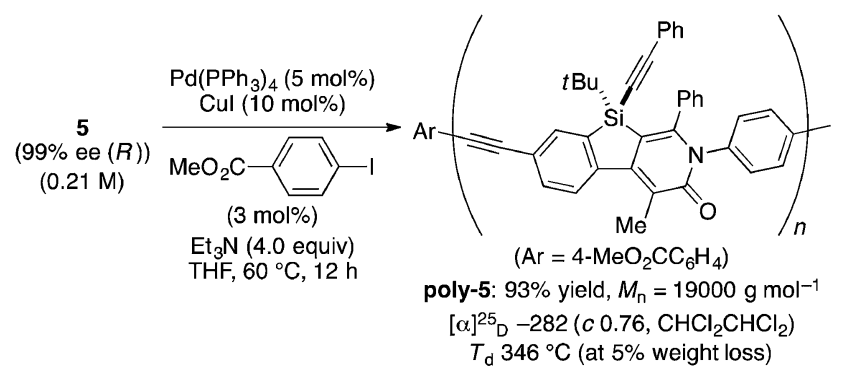

(3) 


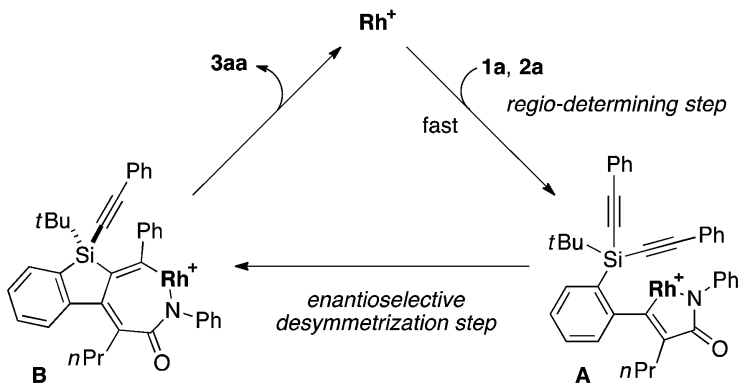

Scheme 1 Proposed catalytic cycle for the rhodium-catalyzed asymmetric $[2+2+2]$ cycloaddition of $1 a$ with $2 a$ to give $3 a a(R h=$ $\operatorname{Rh}((R)-\mathrm{L}))$.

\section{Mechanistic considerations}

To gain some insight into the origin of regioselective formation of compounds 3 in the present catalysis, we conducted control experiments using triynes $\mathbf{1 a}$ and $\mathbf{1 k}$, which possess opposite substitution patterns on arylalkynes $\left(\mathrm{R}^{1}\right)$ and silylalkynes $\left(\mathrm{R}^{2}\right)$ with each other, in the reaction of isocyanate 2 a under $\mathrm{Rh} /(R)-\mathbf{L}$ catalysis (eqn (4)). As was also described in Table 2, entry 1 , the reaction of $\mathbf{1 a}$ with $\mathbf{2 a}$ selectively gave $\mathbf{3 a a}$ as the sole regioisomer in $85 \%$ yield with $89 \%$ ee. The use of $1 \mathbf{k}$ in place of 1a under otherwise the same conditions turned out to give product 3ka as the sole regioisomer as well, although the yield and ee became somewhat lower ( $52 \%$ yield, $43 \%$ ee). These results indicate that the proximal substituents of the alkynes that engage in the $\mathrm{C}-\mathrm{C}$ or $\mathrm{C}-\mathrm{N}$ bond-formation with an isocyanate do not influence the regioselectivity of this process. Instead, the regioselectivity is probably controlled by the reactivity difference between arylalkyne and silylalkyne of triyne $\mathbf{1}$. Based on these results, a proposed catalytic cycle for the reaction of 1a with $\mathbf{2 a}$ is illustrated in Scheme 1. Thus, initial oxidative cyclization of alkyne on the benzene ring of $1 \mathrm{a}$ and $\mathrm{C}=\mathrm{N}$ of $\mathbf{2 a}$ with cationic rhodium(I) species gives fivemembered rhodacycle A having a $\mathrm{Rh}-\mathrm{N}$ bond to set the regiochemistry in the product formation. ${ }^{7 \boldsymbol{d}, \mathbf{1 8}}$ Subsequent intramolecular insertion of one of the alkynes on silicon into the Rh$\mathbf{C}$ bond of $\mathbf{A}$ takes place to give seven-membered rhodacycle $\mathbf{B}$. The enantioselectivity of the silicon stereocenter is presumably determined at this insertion step. Rhodacycle $\mathbf{B}$ then undergoes reductive elimination to provide compound 3 aa along with regeneration of cationic rhodium(I) species.
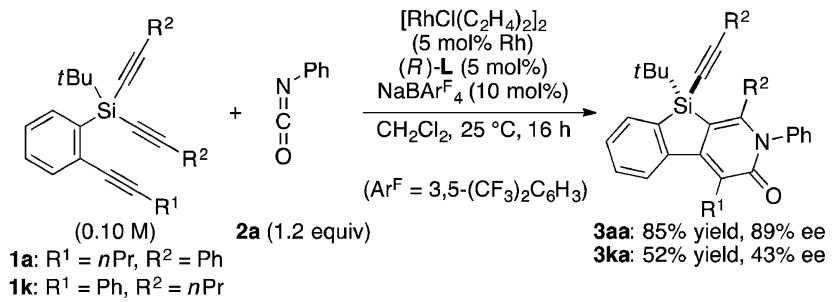

We also carried out a series of kinetic experiments to gain more detailed understanding for the reaction of triyne 1a with

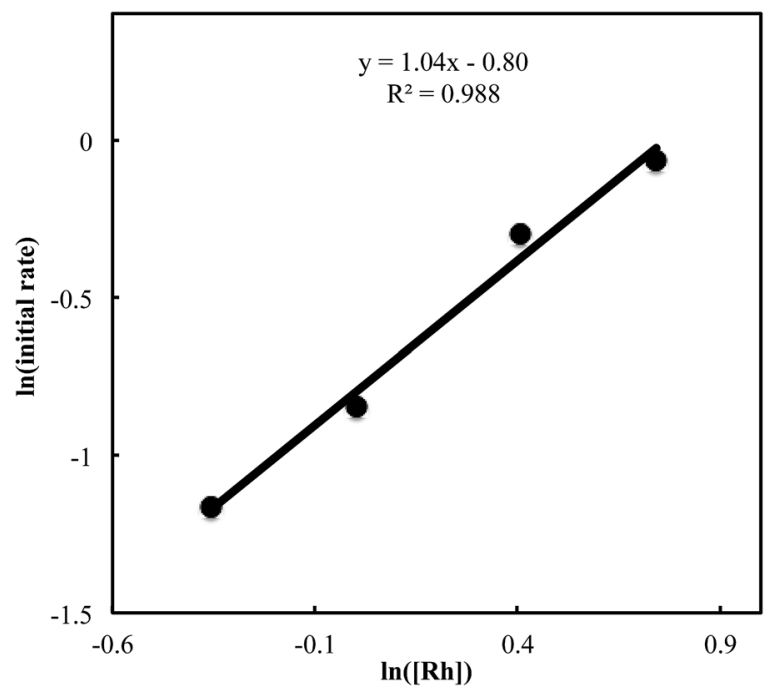

Fig. $4 \mathrm{Ln}$ plot of the initial rate $\left(\mathrm{mM} \mathrm{min}{ }^{-1}\right)$ vs. concentration of Rh catalyst $(\mathrm{mM})\left([\mathrm{Rh}]_{0}=0.7-2.1 \mathrm{mM},[1 \mathrm{a}]_{0}=50 \mathrm{mM},[2 \mathrm{a}]_{0}=50 \mathrm{mM}\right)$.

isocyanate $2 \mathrm{a}$ in the presence of $\left[\mathrm{RhCl}\left(\mathrm{C}_{2} \mathrm{H}_{4}\right)_{2}\right]_{2} /(R)-\mathrm{L} / \mathrm{NaBAr}^{\mathrm{F}}{ }_{4}$ as the catalyst in $\mathrm{CH}_{2} \mathrm{Cl}_{2}$ at $28{ }^{\circ} \mathrm{C}$. As shown in Fig. 4, the reaction rate shows first-order dependency on the concentration of rhodium catalyst. In contrast, the initial concentrations of triyne 1a and isocyanate 2a have no influence on the initial rate of the production of 3aa (Fig. 5 and 6), indicating that the reaction is zero-order in both [1a] and [2a]. These experimental results are consistent with the proposed catalytic cycle in Scheme 1, and the oxidative cyclization step to form intermediate A takes place rapidly (zero-order in both [1a] and [2a]). The turnover-limiting step is one of the subsequent intramolecular processes, either the insertion step to form intermediate $\mathbf{B}$ or the reductive elimination step from $\mathbf{B}$ (first-order in $[\mathbf{R h}]$ ).

Attempted kinetic resolution of triyne $( \pm)$-1l gave further information for the mechanism of the present catalysis. As

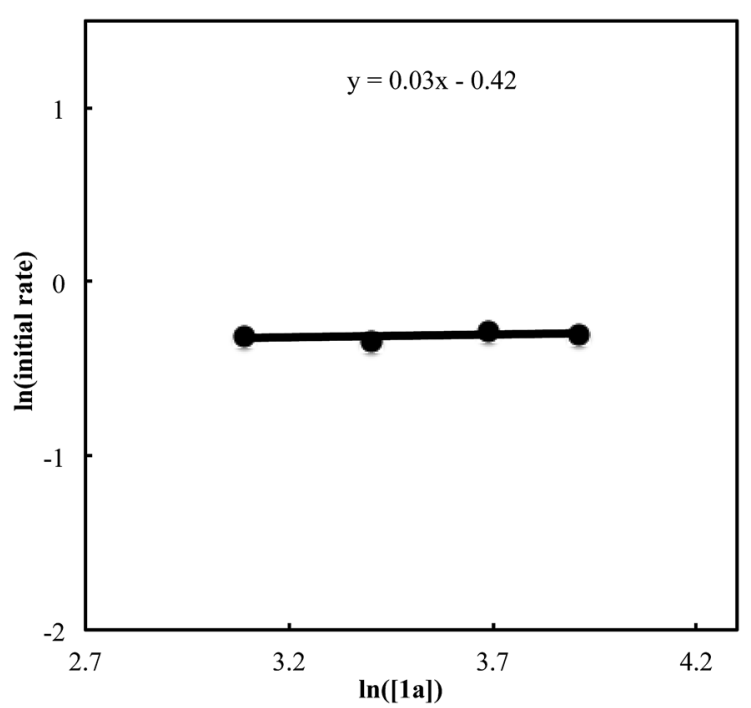

Fig. 5 Ln plot of the initial rate $\left(\mathrm{mM} \mathrm{min}^{-1}\right)$ vs. concentration of triyne $1 \mathrm{a}(\mathrm{mM})\left([\mathrm{Rh}]_{0}=1.5 \mathrm{mM},[1 \mathrm{a}]_{0}=22-50 \mathrm{mM},[2 \mathrm{a}]_{0}=50 \mathrm{mM}\right)$. 


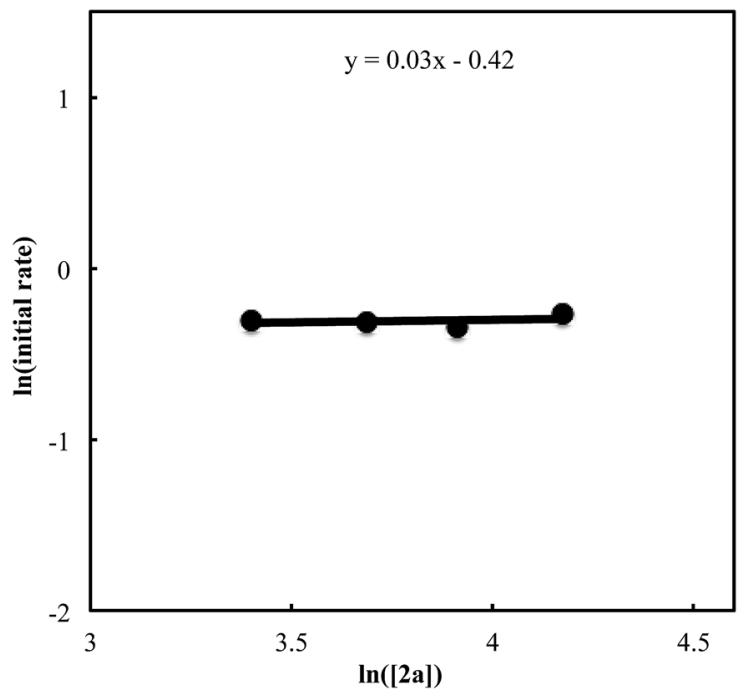

Fig. $6 \mathrm{Ln}$ plot of the initial rate $\left(\mathrm{mM} \mathrm{min}^{-1}\right)$ vs. concentration of isocyanate $2 \mathrm{a}(\mathrm{mM})\left([\mathrm{Rh}]_{0}=1.5 \mathrm{mM},[1 \mathrm{a}]_{0}=30 \mathrm{mM},[2 \mathrm{a}]_{0}=30-\right.$ $65 \mathrm{mM})$.

shown in eqn (5), the reaction of $( \pm)-11$ (2.0 equiv.) with phenyl isocyanate $\mathbf{2 a}$ in the presence of $\mathrm{Rh} /(R)$-L selectively gave product 3la in $97 \%$ yield based on $2 \mathbf{a}$ ( $49 \%$ yield based on $( \pm)-\mathbf{1 1})$ by incorporating the 4-methoxyphenylethynyl group on silicon into the pyridinone framework with trimethylsilylethynyl group intact, and 3la thus obtained was found to be completely racemic. In contrast, enantiopure $(S)-(-)-11$, the matched enantiomer, reacted with $2 \mathrm{a}$ at least 4.2 times faster than its opposite enantiomer $(R)-(+)-\mathbf{1 l}$ under the catalysis of $\mathbf{R h} /(R)-\mathbf{L}$ (eqn (6) and (7)). These results indicate that the initial oxidative cyclization step in Scheme 1 occurs irreversibly and non-stereoselectively, and the subsequent enantio-discriminating insertion step is most likely the turnover-limiting step.

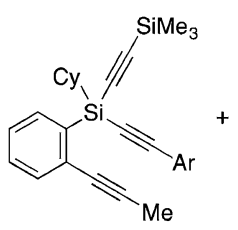

$\left(\mathrm{Ar}=4-\mathrm{MeOC}_{6} \mathrm{H}_{4}\right) \quad 2 \mathrm{a}(0.10 \mathrm{M})$ ( \pm )-11 (2.0 equiv)

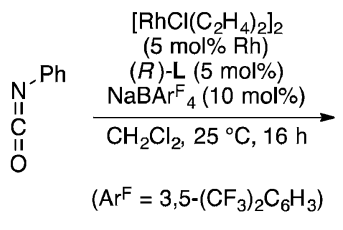

3la: $97 \%$ yield, $0 \%$ ee ( $17 \%$ ee at $16 \%$ yield)

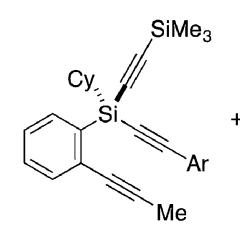

$\left(\mathrm{Ar}=4-\mathrm{MeOC}_{6} \mathrm{H}_{4}\right)$ (S) $-(-)-11$ ( 1.0 equiv)
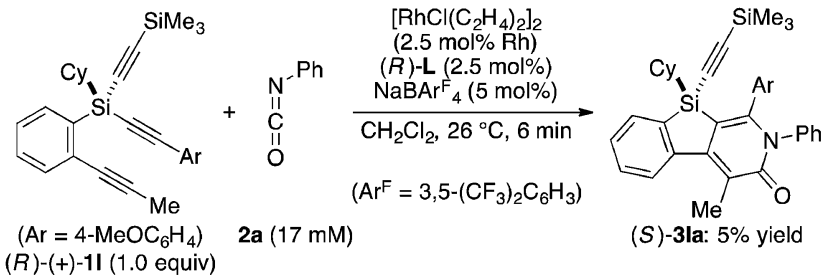

(S)-3la: $5 \%$ yield $(R)-(+)-11$ (1.0 equiv)

\section{Conclusions}

In summary, we have developed a rhodium-catalyzed regio- and enantioselective synthesis of silicon-stereogenic silicon-bridged arylpyridinones through $[2+2+2]$ cycloaddition of siliconcontaining prochiral triynes with isocyanates. High yields and enantioselectivities have been achieved by employing axially chiral monophosphine $(R)-\mathbf{L}$ as the ligand, and this process could be applied to the synthesis of silicon-stereogenic chiral polymers by way of a catalytic asymmetric construction of the silicon stereocenter for the first time. We have also investigated the mechanistic aspects of the present catalysis to establish a reasonable catalytic cycle based on a series of control experiments and kinetic studies, which represents a rare example of the experimental mechanistic study for the rhodium-catalyzed synthesis of pyridinones via $[2+2+2]$ cycloaddition reactions.

\section{Acknowledgements}

Support has been provided in part by a Grant-in-Aid for Challenging Exploratory Research, the Ministry of Education, Culture, Sports, Science and Technology, Japan. We thank Prof. Takuzo Aida at The University of Tokyo for the measurement of fluorescence and CD spectra. We thank Prof. Yoshiaki Nishibayashi and Dr Kazunari Nakajima at The University of Tokyo for the measurement of optical rotations. We thank Dr Shingo Ito for X-ray crystallographic analysis.

\section{Notes and references}

1 (a) Comprehensive Asymmetric Catalysis I-III, ed. E. N. Jacobsen, A. Pfaltz and H. Yamamoto, Springer-Verlag, New York, 1999; (b) Catalytic Asymmetric Synthesis, ed. I. Ojima, Wiley-VCH, New York, 2nd edn, 2000; (c) New Frontiers in Asymmetric Catalysis,ed. K. Mikami and M. Lautens, John Wiley \& Sons, New Jersey, 2007; (d) Phosphorus Ligands in Asymmetric Catalysis 1-3,ed. A. Börner, Wiley-VCH, Weinheim, 2008; (e) Multicatalyst System in Asymmetric Catalysis, ed. J. Zhou, John Wiley \& Sons, New Jersey, 2015.

2 For reviews on catalytic asymmetric synthesis of siliconstereogenic organosilanes, see: (a) L.-W. Xu, L. Li, G.-Q. Lai and J.-X. Jiang, Chem. Soc. Rev., 2011, 40, 1777; (b) L.-W. Xu, Angew. Chem., Int. Ed., 2012, 51, 12932; (c) R. Shintani, Asian J. Org. Chem., 2015, 4, 510.

3 Stoichiometric synthesis of silicon-stereogenic compounds has been somewhat more investigated. For pioneering 
work, see: (a) L. H. Sommer,Stereochemistry, Mechanism and Silicon; an Introduction to the Dynamic Stereochemistry and Reaction Mechanisms of Silicon Centers, McGraw-Hill, New York, 1965 For selected recent examples, see: (b) C. Strohmann, J. Hörnig and D. Auer, Chem. Commun., 2002, 766; (c) M. Trzoss, J. Shao and S. Bienz, Tetrahedron: Asymmetry, 2004, 15, 1501; (d) S. Rendler, G. Auer and M. Oestreich, Angew. Chem., Int. Ed., 2005, 44, 7620; (e) S. Rendler, G. Auer, M. Keller and M. Oestreich, Adv. Synth. Catal., 2006, 348, 1171; $(f)$ S. Rendler, M. Oestreich, C. P. Butts and G. C. Lloyd-Jones, J. Am. Chem. Soc., 2007, 129, 502; $(g)$ K. Igawa, N. Kokan and K. Tomooka, Angew. Chem., Int. Ed., 2010, 49, 728; (h) J. O. Bauer and C. Strohmann, Angew. Chem., Int. Ed., 2014, 53, 720.

4 (a) R. J. P. Corriu and J. J. E. Moreau, Tetrahedron Lett., 1973, 14, 4469; (b) T. Hayashi, K. Yamamoto and M. Kumada, Tetrahedron Lett., 1974, 15, 331; (c) R. J. P. Corriu and J. J. E. Moreau, J. Organomet. Chem., 1975, 85, 19; (d) R. J. P. Corriu and J. J. E. Moreau, J. Organomet. Chem., 1976, 120, 337; (e) T. Ohta, M. Ito, A. Tsuneto and H. Takaya, J. Chem. Soc., Chem. Commun., 1994, 2525; $(f)$ Y. Yasutomi, H. Suematsu and T. Katsuki, J. Am. Chem. Soc., 2010, 132, 4510; (g) Y. Kurihara, M. Nishikawa, Y. Yamanoi and H. Nishihara, Chem. Commun., 2012, 48, 11564; (h) K. Igawa, D. Yoshihiro, N. Ichikawa, N. Kokan and K. Tomooka, Angew. Chem., Int. Ed., 2012, 51, 12745 See also: (i) K. Tamao, K. Nakamura, H. Ishii, S. Yamaguchi and M. Shiro, J. Am. Chem. Soc., 1996, 118, 12469; (j) D. R. Schmidt, S. J. O'Malley and J. L. Leighton, J. Am. Chem. Soc., 2003, 125, 1190; (k) Y. Kuninobu, K. Yamauchi, N. Tamura, T. Seiki and K. Takai, Angew. Chem., Int. Ed., 2013, 52, 1520.

5 (a) K. Igawa, J. Takada, T. Shimono and K. Tomooka, J. Am.Chem. Soc., 2008, 130, 16132; (b) R. Shintani, K. Moriya and T. Hayashi, J. Am. Chem. Soc., 2011, 133, 16440; (c) R. Shintani, K. Moriya and T. Hayashi, Org. Lett., 2012, 14, 2902; (d) R. Shintani, H. Otomo, K. Ota and T. Hayashi, J. Am. Chem. Soc., 2012, 134, 7305; (e) R. Shintani, E. E. Maciver, F. Tamakuni and T. Hayashi, J. Am. Chem. Soc., 2012, 134, 16955; (f) M. Onoe, K. Baba, Y. Kim, Y. Kita, M. Tobisu and N. Chatani, J. Am. Chem. Soc., 2012, 134, 19477; (g) X. Lu, L. Li, W. Yang, K. Jiang, K.-F. Yang, Z.-J. Zheng and L.-W. Xu, Eur. J. Org. Chem., 2013, 5814; (h) R. Shintani, C. Takagi, T. Ito, M. Naito and K. Nozaki, Angew. Chem., Int. Ed., 2015, 54, 1616; (i) Y. Naganawa, T. Namba, M. Kawagishi and H. Nishiyama, Chem.-Eur. J., 2015, 21, 9319; (j) R. Shintani, H. Kurata and K. Nozaki, Chem. Commun., 2015, 51, 11378.

6 For recent reviews on the rhodium-catalyzed $[2+2+2]$ cycloaddition reactions, see: (a) K. Tanaka, Chem.-Asian J., 2009, 4, 508; (b) N. Weding and M. Hapke, Chem. Soc. Rev., 2011, 40, 4525; (c) Y. Shibata and K. Tanaka, Synthesis, 2012, 44, 323; (d) D. L. J. Broere and E. Ruijter, Synthesis, 2012, 44, 2639; (e) K. Tanaka, Y. Kimura and K. Murayama, Bull. Chem. Soc. Jpn., 2015, 88, 375.

7 For examples of pyridinone synthesis by rhodium-catalyzed $[2+2+2]$ cycloaddition reactions: (a) S. T. Flynn,
S. E. Hasso-Henderson and A. W. Parkins, J. Mol. Catal., 1985, 32, 101; (b) K. Tanaka, A. Wada and K. Noguchi, Org. Lett., 2005, 7, 4737; (c) G. Nishida, N. Suzuki, K. Noguchi and K. Tanaka, Org. Lett., 2006, 8, 3489; (d) T. Kondo, M. Nomura, Y. Ura, K. Wada and T. Mitsudo, Tetrahedron Lett., 2006, 47, 7107; (e) K. Tanaka, Y. Takahashi, T. Suda and M. Hirano, Synlett, 2008, 1724; $(f)$ K. M. Oberg, E. E. Lee and T. Rovis, Tetrahedron, 2009, 65, 5056; $(g)$ Y. Komine and K. Tanaka, Org. Lett., 2010, 12, 1312; (h) M. Augé, M. Barbazanges, A. T. Tran, A. Simonneau, P. Elley, H. Amouri, C. Aubert, L. Fensterbank, V. Gandon, M. Malacria, J. Moussa and C. Ollivier, Chem. Commun., 2013, 49, 7833; (i) M. Augé, A. Feraldi-Xypolia, M. Barbazanges, C. Aubert, L. Fensterbank, V. Gandon, E. Kolodziej and C. Ollivier, Org. Lett., 2015, 17, 3754 For a review: (j) K. Tanaka, Heterocycles, 2012, 85, 1017.

8 Other transition-metal catalysts have also been used for pyridinone synthesis by $[2+2+2]$ cycloaddition. Cobalt: (a) P. Hona and H. Yamazaki, Tetrahedron Lett., 1977, 1333; (b) R. A. Earl and K. P. C. Vollhardt, J. Am. Chem. Soc., 1983, 105, 6991; (c) R. A. Earl and K. P. C. Vollhardt, J. Org. Chem., 1984, 49, 4786; (d) P. Diversi, G. Ingrosso, A. Lucherini and S. Malquori, J. Mol. Catal., 1987, 40, 267; (e) L. V. R. Boñaga, H.-C. Zhang, D. A. Gauthier, I. Reddy and B. E. Maryanoff, Org. Lett., 2003, 5, 4537; $(f)$ L. V. R. Boñaga, H.-C. Zhang, A. F. Moretto, H. Ye, D. A. Gauthier, J. Li, G. C. Leo and B. E. Maryanoff, J. Am. Chem. Soc., 2005, 127, 3473; (g) D. D. Young and A. Deiters, Angew. Chem., Int. Ed., 2007, 46, 5187; $(h)$ D. D. Young, J. A. Teske and A. Deiters, Synthesis, 2009, 3785; (i) L. L. Lv, X. F. Wang, Y. C. Zhu, X. W. Liu, X. Q. Huang and Y. C. Wang, Organometallics, 2013, 32, 3837 Nickel: (j) H. Hoberg and B. W. Oster, Synthesis, 1982, 324; (k) H. Hoberg and B. W. Oster, J. Organomet. Chem., 1983, 252, 359; (l) H. A. Duong, M. J. Cross and J. Louie, J. Am. Chem. Soc., 2004, 126, 11438; (m) H. A. Duong and J. Louie, $J$. Organomet. Chem., 2005, 690, 5098 Ruthenium: (n) Y. Yamamoto, H. Takagishi and K. Itoh, Org. Lett., 2001, 3, 2117; (o) S. Alvarez, S. Medina, G. Domínguez and J. PérezCastells, J. Org. Chem., 2013, 78, 9995 Iridium: (p) G. Onodera, M. Suto and R. Takeuchi, J. Org. Chem., 2012, 77, 908.

9 H. Takaya, K. Mashima, K. Koyano, M. Yagi, H. Kumobayashi, T. Taketomi, S. Akutagawa and R. Noyori, J. Org. Chem., 1986, 51, 629.

10 X. Zhang, K. Mashima, K. Koyano, N. Sayo, H. Kumobayashi, S. Akutagawa and H. Takaya, Tetrahedron Lett., 1991, 32, 7283.

11 T. Saito, T. Yokozawa, T. Ishizaki, T. Moroi, N. Sayo, T. Miura and H. Kumobayashi, Adv. Synth. Catal., 2001, 343, 264.

12 (a) T. Hayashi, Acc. Chem. Res., 2000, 33, 354; (b) Y. Uozumi, A. Tanahashi, S.-Y. Lee and T. Hayashi, J. Org. Chem., 1993, 58, 1945.

13 B. Saha and T. V. RajanBabu, J. Org. Chem., 2007, 72, 2357. 14 CCDC-1428796 contains the supplementary crystallographic data for this paper. 
15 (a) R. Shintani, T. Ito, M. Nagamoto, H. Otomo and T. Hayashi, Chem. Commun., 2012, 48, 9936 See also: (b) T. M. Ha, B. Yao, Q. Wang and J. Zhu, Org. Lett., 2015, 17, 1750.

16 Polymerization of 5 in the absence of initiator also proceeded smoothly to give highly insoluble polymers, presumably due to the formation of polymers with much higher molecular weight. In order to enable solution-phase analyses of the polymers, we conducted polymerization using $3 \mathrm{~mol} \%$ of methyl 4-iodobenzoate to obtain polymers with a controlled number average molecular weight.

17 Optically active silicon-stereogenic chiral polymers containing silicon atoms in the main chain have been reported through the chiral HPLC separation of racemic monomers: (a) Y. Kawakami, M. Omote, I. Imae and E. Shirakawa, Macromolecules, 2003, 36, 7461; (b) D. Zhou and Y. Kawakami, Macromolecules, 2005, 38, 6902 Optically active silicon-stereogenic chiral polymers containing silicon atoms in the side chain have been reported through the fractional recrystallization of diastereomeric monomers: (c) B. Z. Tang, X. Wan and H. S. Kwok, Eur. Polym. J., 1998, 34, 341.

18 Related azametallacycle intermediates have also been proposed for other transition-metal catalyst systems. See ref. $8 \mathrm{~d}, \mathrm{k}$, and $\mathrm{m}$. 